\title{
THE TECHNOLOGY FOR THE REDUCTION OF METAL OXIDES USING WASTE POLYETHYLENE MATERIALS
}

\author{
Shokhrukh Toshpulatovich KHOJIEV, Sokhibjon Turdalievich MATKARIMOV, \\ Etibor Tukhtaboy kizi NARKULOVA, Zaynobiddin Turdalievich MATKARIMOV, \\ Nasiba Saidakhmatovna YULDASHEVA \\ Department of Mining and Metallurgy, Tashkent State Technical University, Tashkent, Uzbekistan, \\ hojiyevshohruh@yandex.ru, a.yusupkhodjayev@mail.ru, sohibtm@gmail.com,.mr.berdiyarov@mail.ru, \\ gahramonochildiyev@gmail.com
}

https://doi.org/10.37904/metal.2020.3592

\begin{abstract}
The study relates to the processing of zinc-containing wastes of metallurgical production using products of joint pyrolysis of polyethylene wastes and wood pods. The process is carried out in two stages: preparation of polyethylene waste for the operation and then the recovery process. Zinc-containing wastes are thickened, dehydrated to a moisture content of not more than $10-13 \%$, mixed with a reducing agent. Dehydrated Zinccontaining wastes (cake or sludge) are mixed with synthetic reducing agents in a mass ratio cake - artificial reducing agent from 8.8: 2.2 to 8.2: 2.8 , respectively, and pelletized. They carry out reductive heat treatment of pelletized waste in the presence of a reliable carbon-containing reducing agent in the amount of $20-40 \%$ by weight of the processed waste and the resulting products of the combined pyrolysis of polyethylene waste and wood pods with counter current air blasting in a rotary kiln, distillation of zinc and trapping of sublimates to produce zinc oxides. Moreover, before igniting a reliable, reducing agent and pyrolysis products of polyethylene wastes (synthetic reducing agent), gaseous fuel is burned in the working volume of the furnace. This study will increase the intensity of the processes of sublimation of zinc and reduction of iron, increase the degree of utilization of polymer waste.
\end{abstract}

Keywords: Polyethylene waste, metallurgical waste, pyrolysis, recycling, Waelz kiln

\section{INTRODUCTION}

In almost all countries of the world, municipal solid waste per capita increases by one percent annually. This, in turn, harms global environmental sustainability. According to experts, more than 800 types of waste are currently registered, and emission standards may increase in the future. The primary source of environmental pollution is waste generated from materials used in energy, non-ferrous and ferrous metallurgy, chemical and construction industries. Ignoring them can lead to unexpected changes in natural resources and nature. This is because even natural products can be absorbed and absorbed into the soil. For example, the paper will rot only three months after it is discarded. The complete separation of plastic and plastic bags into biological components takes 400-450 years, and glass can completely disappear after a million years [1].

The burning of polyethylene waste in nature causes harm to the environment (including trees and shrubs growing in the garden) and the health of all living organisms (Figure 1).

In Uzbekistan, the amount of generated waste per person per day is $0.6-0.8 \mathrm{~kg}$, and from the entire population of 18 - 20 thousand tons.

In the regions, according to the morphological composition of waste in 2018,565.6 thousand tons of polymer and polyethylene (7.91\%), 98.6 thousand tons of metal (ferrous and non-ferrous metals, $1.38 \%$ ), 923.2 
thousand were generated tons of crop (12.91\%), 163.7 thousand tons of leather, rubber, bone (2.29\%), 101.5 thousand tons of wood (1.42\%), 2.3 million tons of other waste forks ( $31.83 \%)$.

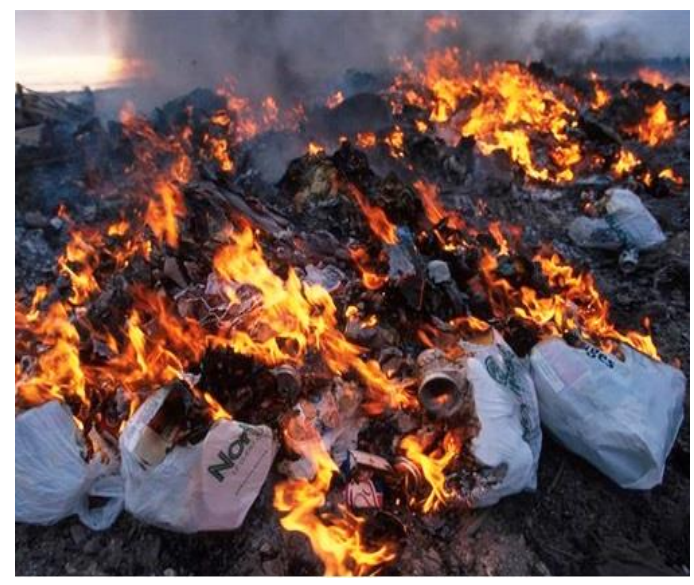

Figure 1 Ecological pollution with the burning of polyethylene waste

It is worth noting that $80 \%$ of these wastes are organic substances, and their processing can produce a large amount of energy. Including these natural substances are the sources of reducing agent in the production of metals. According to experts, household waste is the cheapest raw material in the world [2].

Including waste from mining and metallurgical enterprises brings great harm to the environment.

One of the wastes of metallurgical production in the Almalyk zinc plant (in Uzbekistan) is clinker. It contains over $2.20 \%$ copper, $2.40 \%$ zinc, $0.01 \%$ cadmium, $5-8 \mathrm{~g} / \mathrm{t}$ gold, $250-500 \mathrm{~g} / \mathrm{t}$ silver and many other valuable components [3].

A tailing dump and, especially, slag dumps attack the suburban territory, occupy thousands of hectares of farmland, pollute the air basin and disfigure the landscape. Assessment of damage from environmental pollution leads to a significant expansion of the boundaries of the economic feasibility of creating and applying waste-free technology. Given this circumstance, of course, the economic efficiency of combining industries increases and new criteria arise for the formation of production structures in industry related to environmental protection [4].

The involvement of these technogenic formations using polyethylene waste will allow the plant to obtain thousands of tons of copper and zinc, tens of thousands of tons of iron. Also, with the use of polyethylene waste as a reducing agent for metal production, it prevents environmental pollution [5].

In this regard, the task of creating an intelligent and integrated technology for the processing of slag and intermediate products of copper and zinc production using polyethylene waste as a reducing agent is very relevant [6].

The purpose of the work is to expand the raw material base of mining and metallurgical enterprises with the direction of polyethylene waste as a reducing agent in metallurgy [7].

\section{LITERATURE REVIEW}

The prior art method for sorting and processing municipal solid waste: The known method includes the collection of waste, its transportation by garbage trucks, unloading the latter, preliminary sorting of garbage with the extraction of bulky items, feeding the remaining waste to the sorting conveyor with the removal of various types of waste, first manually, then by mechanical selection and moving unused waste to the empty bins of the garbage trucks [8]. 
The main disadvantage of this method is that the waste in the process of collection and transportation are mixed and pressed. Which significantly reduces the efficiency of subsequent sorting? Besides, it is becoming increasingly difficult for heavy-duty garbage trucks to transport waste from yard areas due to the increasing number of personal vehicles.

Including, there is a known method of economical transportation, collection, sorting, and disposal of household waste. The method includes preliminary partial sorting of waste by type at the place of gathering of waste by the population at container sites, transportation of waste to an intermediate collection point, complete and final sorting at a middle collection point, and delivery of sorted waste to industrial enterprises for secondary use [9].

Now consider the current state of metallurgical waste processing using examples of zinc production.

There is a method of Waelz of zinc-containing materials with the introduction of the mixture, coke, and obtaining clinker [10].

The disadvantage of this method is that when Wielding uses an excessive amount of expensive, reliable, reducing agents (coke breeze fossil fuels).

It is known a method of Waelz of zinc-containing materials with a dosage in the mixture of calcium-containing flux, in particular calcium oxide [11].

The disadvantage of this method is the loading of calcium oxide together with the charge from the top-loading end of the furnace, which leads to an increase in the formation of crusts in the drying zone and the recovery of the load during the processing of zinc cakes and certain types of slag and the same when using Waelz using an expensive reliable, reducing agent (coke breeze).

The closest in technical essence and the achieved result to the study is a method of processing zinc-containing wastes of metallurgical production [12], developed by the Ukrainian State Scientific and Technical Center "Energostal," which includes:

- $\quad$ dehydration of sludge to a moisture content of $6-10 \%$;

- adding to the dehydrated sludge dehydrated oily scale of the rolling mill in an amount of $10-50 \%$ by weight of sludge;

- $\quad$ uniform mixing of slurry with greasy size and the fluxing of the mixture by adding finely divided waste products of lime or calcium carbide in an amount of $3-15 \%$ by weight of a combination of sludge and oily scale;

- $\quad$ reductive heat treatment of the resulting mixture in a tubular rotary kiln without oxygen access by natural gas combustion products or the fuel fraction of the distillation of liquid dehydrated oil waste (counter flow) obtained with an airflow coefficient of $0.5-0.9$ and a temperature of $1150-1450{ }^{\circ} \mathrm{C}$ with a vacuum of a system of $15-160 \mathrm{~Pa}$ and an exhaust gas temperature of $450-700{ }^{\circ} \mathrm{C}$;

- dust collection in exhaust gases due to the operation of bag filters;

- cooling the obtained calcined product.

As a result of the implementation of this method of processing finely dispersed iron-zinc-containing wastes from metallurgical industries, two end products similar to the above are obtained that are suitable for use in sintering and steelmaking.

However, the method developed by "UkrGSTC Energostal" and based on the replacement of a reliable, reducing agent with liquid (oil waste contained in oily scale) and hot reducing gases (products of burning natural gas or the fuel fraction of the distillation of liquid dehydrated oil waste) has the following disadvantages:

- $\quad$ a necessary condition for the process is the presence of oily scale;

- the complexity of the technological scheme for processing iron-containing sludge, which includes the separate supply to the processing site of iron-zinc-containing sludge and greasy scale, the preparation of hot reducing gases, which involves the distillation of oil waste and their preliminary combustion before 
being fed into the furnace, providing a vacuum in the system, afterburning of furnace gases with a high reduction potential.

A common disadvantage of these methods is that in these works, there is no complexity in the joint processing of polyethylene and metallurgical wastes.

The objective of the study is the maximum possible removal of zinc from zinc-containing wastes (cakes, sludges) of metallurgical production, environmental protection through the disposal of polymer wastes, and the reduction of economic costs when using a carbon-reducing agent obtained after processing polyethylene waste.

\section{OBJECTS AND RESEARCH METHODS}

The objects of the study of this work are waste plastic bags (Figure 2) and zinc cake, the composition of which is given in Table 1.

Table 1 The chemical composition of zinc cakes

\begin{tabular}{|c|c|c|c|c|c|c|c|c|c|c|}
\hline \multirow{2}{*}{$\begin{array}{c}\text { Sample } \\
\text { No. }\end{array}$} & \multicolumn{10}{|c|}{ Components (wt\%) } \\
\cline { 2 - 12 } & $\mathbf{Z n}$ & $\mathbf{P b}$ & $\mathbf{C u}$ & $\mathbf{C d}$ & $\mathbf{F e}$ & $\mathbf{S}$ & $\mathbf{S i O}_{2}$ & $\mathbf{C a O}$ & $\mathbf{M g O}$ & Other \\
\hline 1 & 16.5 & 5.6 & 1.4 & 0.3 & 31.5 & 9.7 & 10.9 & 3.0 & 1.1 & 20.0 \\
\hline 2 & 20.5 & 3.6 & 0.7 & 0.2 & 28.7 & 8.8 & 12.3 & 2.7 & 1.2 & 21.3 \\
\hline 3 & 18.9 & 5.9 & 1.5 & 0.1 & 32.2 & 10.7 & 8.7 & 3.5 & 0.4 & 18.1 \\
\hline 4 & 21.2 & 6.8 & 2.1 & 0.4 & 26.8 & 7.2 & 11.5 & 3.5 & 0.9 & 19.6 \\
\hline 5 & 22.8 & 2.7 & 1.8 & 0.3 & 30.6 & 9.5 & 8.9 & 1.9 & 1.1 & 20.4 \\
\hline
\end{tabular}

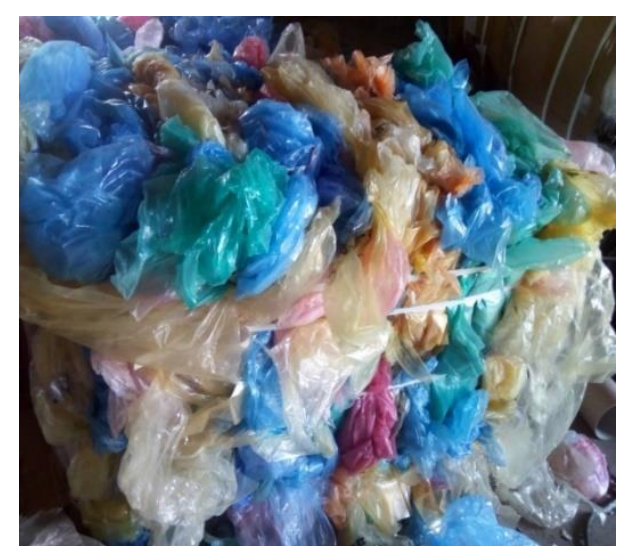

Figure 2 Briquetted plastic bags

The process is carried out in two stages:

1) preparation of polyethylene waste for the process;

2) recovery process.

For the processing of zinc cake (sludge) using polyethylene waste, a unique synthetic reducing agent is first prepared as follows:

- $\quad$ chopped reed or wood pods;

- a scrap of polymer products is melted with burning at $100-300{ }^{\circ} \mathrm{C}$ together with a wood pod (the mass ratio between the waste of polymer products and a wood pod is $4:(1 \div 2)$, respectively. The duration of the process depends on the amount of the starting reagent. The process is subjected to pyrolysis furnaces (Figure 3 ); 
- $\quad$ the result is a synthetic reducing agent and is cooled at $20-25^{\circ} \mathrm{C}$;

- $\quad$ after cooling, the finished artificial reducing agent is crushed before use. The chemical composition of the synthetic reducing agent is shown in Table 2.

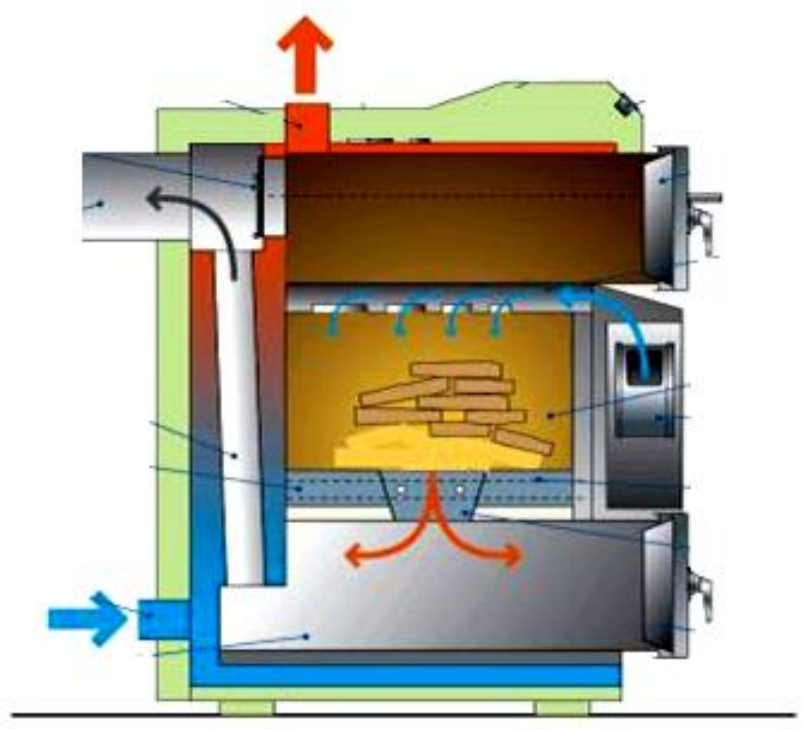

Figure 3 Oven for pyrolysis of a mixture of wood pods and polyethylene waste

The recovery process for the processing of zinc-containing wastes of metallurgical production using pyrolysis products of polyethylene waste is carried out as follows:

- $\quad$ first, zinc cakes (or sludges) are thickened and dehydrated using known methods until the moisture content in them is not more than $10 \%$, then they are pelletized with the addition of a binder in the form of a synthetic reducing agent in an amount of $10-20 \%$ by weight of cakes (or sludges);

- then pelletized slabs (sludges) are subjected to heat treatment in a rotary tube furnace (Waelz furnace, Figure 4). In parallel with pelletized slurries, a reliable, reducing agent is fed into the stove (a mixture of the synthetic reducing agent with coke, coke battery slimes and dry coke quenching units, coke breeze, fossil fuels, etc.) in an amount of $20-40 \%$ by weight of pelletized cake (sludge).

Table 2 The chemical composition of the synthetic reducing agent after thermal processing of the mixture

\begin{tabular}{|c|c|c|c|c|}
\hline \multirow{2}{*}{$\begin{array}{c}\text { Sale } \\
\text { No }\end{array}$} & \multicolumn{4}{|c|}{ Components (\%) } \\
\cline { 2 - 5 } & C & H & Ash & Reducing part \\
\hline 1 & 76.45 & 11.89 & 11.66 & 88.34 \\
\hline 2 & 74.67 & 10.12 & 15.21 & 84.79 \\
\hline 3 & 77.14 & 12.86 & 10.00 & 90.00 \\
\hline 4 & 76.77 & 12.05 & 11.18 & 88.82 \\
\hline 5 & 78.19 & 13.11 & 8.70 & 91.30 \\
\hline
\end{tabular}

To obtain the basicity of the final product $\left(\mathrm{CaO} / \mathrm{SiO}_{2}\right.$ ratio) equal to $0.6-1$, which provides the most favorable conditions for the decomposition of difficultly reduced zinc compounds (ferrites, silicates, sulphides, etc.), it favorably affects the course of iron reduction. It thereby improves the process of removing zinc from the processed material, if necessary, fluxing is added to them during the pelletizing of zinc-containing cakes (sludges) (finely dispersed waste from the production of lime, calcium carbide or roasting of dolomite that) in a given quantity. 


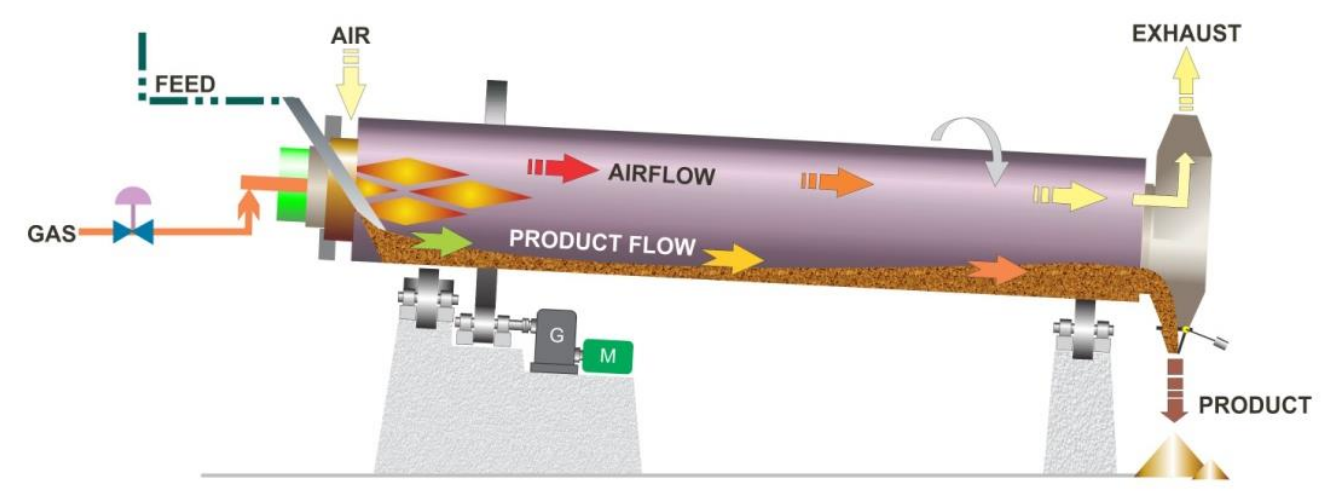

Figure 4 The furnace for pyrometallurgical reduction zinc cakes (Rotary kiln for zinc production)

\section{THE RESULTS OBTAINED AND THEIR DISCUSSION}

Heat treatment of zinc cakes (sludges) is carried out due to the release of heat by a solid reducing agent entering the furnace in parallel with pelletized cakes (sludges) during its combustion and the pyrolysis products of a synthetic reducing agent (light fractions). At $1000-1100{ }^{\circ} \mathrm{C}$, the synthetic reducing agent decomposes into its constituents. The chemical reaction of the decomposition of a synthetic reducing agent (an example of polyethylene waste):

$\left(\mathrm{C}_{2} \mathrm{H}_{4}\right)_{\mathrm{n}} \rightarrow 2 \mathrm{nC}+2 \mathrm{nH}_{2}$

Both of these reagents reduce zinc and iron from their oxides.

Heating of the reaction mixture (pelletized cake or sludge and reliable, reducing agent) before igniting the reliable, reducing agent is carried out by burning gaseous fuel (natural gas or a mixture of natural and blast furnace gas, or a combination of natural and coke oven gas, or coke oven gas) in the working volume of the furnace from its discharge the end. After the ignition of the reliable, reducing agent, the supply of gaseous fuel is stopped.

To maintain the combustion of the reliable, reducing agent, an air blast is introduced into the furnace.

The temperature of the reaction mass in the volume of the working space of the furnace can vary from $30-40{ }^{\circ} \mathrm{C}$ when it is loaded into the furnace and up to $900-1100{ }^{\circ} \mathrm{C}$ when it is unloaded. The temperature of the exhaust gas gases is $600-800^{\circ} \mathrm{C}$. At $900-1100^{\circ} \mathrm{C}$, a reducing reaction of zinc proceeds:

$\mathrm{ZnO} \cdot \mathrm{Fe}_{2} \mathrm{O}_{3}+2 \mathrm{C}=\mathrm{Zn}$ (vap) $+2 \mathrm{Fe}+2 \mathrm{CO}_{2}$

$\mathrm{ZnO} \cdot \mathrm{Fe}_{2} \mathrm{O}_{3}+4 \mathrm{H}_{2}=\mathrm{Zn}$ (vap) $+2 \mathrm{Fe}+4 \mathrm{H}_{2} \mathrm{O}$

$\mathrm{ZnO} \cdot \mathrm{Fe}_{2} \mathrm{O}_{3}+2 \mathrm{Fe}=\mathrm{Zn}_{\text {(vap) }}+4 \mathrm{FeO}$

$\mathrm{ZnO}+\mathrm{CO}=\mathrm{Zn}$ (vap) $+\mathrm{CO}_{2} ; \mathrm{CO}_{2}+\mathrm{C}=2 \mathrm{CO}$

$\mathrm{ZnO} \cdot \mathrm{Fe}_{2} \mathrm{O}_{3}+4 \mathrm{CO}=\mathrm{Zn}$ (vap) $+2 \mathrm{Fe}+4 \mathrm{CO}_{2}$

$2 \mathrm{ZnO} \cdot \mathrm{SiO}_{2}+2 \mathrm{Fe}=2 \mathrm{FeO} \cdot \mathrm{SiO}_{2}+\mathrm{Zn}$ (vap)

$\mathrm{ZnS}+\mathrm{Fe}=\mathrm{FeS}+\mathrm{Zn}$ (vap)

After the heat treatment, the calcined iron-zinc-containing waste, in the form of a pelletized product, in a mixture with an unburnt reliable, reducing agent, is discharged from the furnace, cooled, subjected to magnetic separation and sent to the consumer. The non-magnetic fraction (not burnt reliable, reducing agent) is sent back to the rotary kiln.

Exhaust gases containing dust pass through a gas purification system, where a more significant dust fraction (dust chamber) is separated, and a smaller one containing zinc oxide remains in the bag filters after gas purification in them. 
The heat of the exhaust gases can be disposed of in a waste heat boiler to produce electricity or during the preparation of a synthetic reducing agent (maintaining an operating temperature of $80-90{ }^{\circ} \mathrm{C}$, at which the artificial reducing agent (polymer waste) has the highest fluidity).

To create the necessary conditions for the processes of reduction of zinc and iron compounds, sublimation and removal of zinc and other volatile impurities with furnace gases, to ensure the optimal heat balance of heat treatment of sludge and to prevent the formation of crusts in the furnace, coke breeze is fed into the oven along with the pelletized waste. The ratio of components in the cake - synthetic reducing agent mixture and the degree of zinc extraction into the finished product are presented in Table 3 . The results of the chemical analysis of clinker after Waelz are shown in Table 4.

Table 3 The chemical composition of Waelz oxides

\begin{tabular}{|c|c|c|c|c|c|c|}
\hline \multirow{2}{*}{$\begin{array}{c}\text { Sample } \\
\text { NNo }\end{array}$} & \multirow{2}{*}{$\begin{array}{c}\text { A mass ratio of components } \\
\text { in a mixture of cake - } \\
\text { synthetic reducing agent }\end{array}$} & \multicolumn{4}{|c|}{ Components (wt\%) } & \multirow{2}{*}{$\begin{array}{c}\text { Extraction of zinc in } \\
\text { Waelz oxides from } \\
\text { cake }\end{array}$} \\
\hline 1 & $8.8: 2.2$ & $\mathbf{P b}$ & $\mathbf{C d}$ & Other & \begin{tabular}{c} 
Zn \\
\cline { 3 - 6 }
\end{tabular} \\
\hline 2 & $8.5: 2.5$ & 69.7 & 14.3 & 1.1 & 14.9 & 93.4 \\
\hline 3 & $8.4: 2.6$ & 71.3 & 10.2 & 0.6 & 17.9 & 93.7 \\
\hline 4 & $8.3: 2.7$ & 68.8 & 15.1 & 0.7 & 15.4 & 94.5 \\
\hline 5 & $8.2: 2.8$ & 70.1 & 14.9 & 1.0 & 14.0 & 95.8 \\
\hline
\end{tabular}

The presented tabular data indicate that the proposed method allows to achieve the maximum degree of removal of zinc and other volatile impurities (non-ferrous metal compounds) from the processed materials, to provide a pelletized product that meets the requirements for raw materials used in sintering and steelmaking, and zinc concentrate suitable for use as a raw material in non-ferrous metallurgy.

Table 4 The chemical composition of zinc clinker

\begin{tabular}{|c|c|c|c|c|c|c|c|c|}
\hline \multirow{2}{*}{$\begin{array}{c}\text { Sample } \\
\text { NNo }\end{array}$} & $\begin{array}{c}\text { A mass ratio of } \\
\text { components in a mixture of } \\
\text { cake - synthetic reducing } \\
\text { agent }\end{array}$ & $\mathbf{Z n}$ & $\mathbf{C u}$ & $\mathbf{F e}$ & $\mathbf{S}$ & $\mathbf{S i O}_{2}$ & $\mathbf{C}$ & Other \\
\cline { 5 - 11 } & & & & & & & & \\
\hline 1 & $8.8: 2.2$ & 1.02 & 2.70 & 37.2 & 4.1 & 19.4 & 15.4 & 20.18 \\
\hline 2 & $8.5: 2.5$ & 0.95 & 2.96 & 34.5 & 3.4 & 17.5 & 15.1 & 25.59 \\
\hline 3 & $8.4: 2.6$ & 0.74 & 3.10 & 31.4 & 2.5 & 18.3 & 18.7 & 25.26 \\
\hline 4 & $8.3: 2.7$ & 0.77 & 2.63 & 35.1 & 3.8 & 16.8 & 17.4 & 23.50 \\
\hline 5 & $8.2: 2.8$ & &
\end{tabular}

\section{CONCLUSION}

Thus, the proposed method for the integrated processing of zinc-containing waste from metallurgical industries, based on the use of a synthetic reducing agent as a binder with reducing properties, in the preparation (preparation of pellets or briquettes) of processed materials for heat treatment in a tubular rotary kiln allows:

1) to utilize the waste of polymer products to obtain a synthetic reducing agent for the processing of zinc cakes; 
2) to receive due to the allocation of an artificial reducing agent during its pyrolysis in the process of the regenerative firing of pelletized waste (pellets or briquettes) of hydrocarbon compounds a more porous structure of the resulting product;

3) get a higher degree of sublimation of zinc and other volatile metals (up to $98 \%$ );

4) to provide the most favorable conditions for the process of reduction of iron oxides, zinc compounds and the removal of its vapours with exhaust gases without reducing the total iron content in the final product;

5) to obtain a pelletized metalized product from the initial charge, both containing oily scale and not containing it;

6) reduce total capital costs by partially reducing the high level of consumption of expensive coke used to carry out the process, and replacing it with a relatively cheap reducing agent - waste from polymer production;

7) when conducting the technological process, use a broader range of fluxing materials (both siliconcontaining and calcium- and magnesium-containing) and obtain a product with a given basicity value $\left(\mathrm{CaO} / \mathrm{SiO}_{2}\right)$ depending on the required benefits of the degree of metallization of the finished product and its zinc content and sulphur. Besides, this reduces the cost of environmental measures and specialized equipment for the disposal of polymer waste that pollutes the environment.

\section{REFERENCES}

[1] RAKHIMOV, V. R., ALIMHADZHIEV, S. R., SAIDAHMEDOV, H. S. Raw material supply in the mining industry of Uzbekistan. Mountain Journal. 2001, no. 8. pp. 3-5.

[2] SHAYAKUBOV, T. Sh. The mineral resource base of the Republic of Uzbekistan and problems of its development. Geology and Mineral Resources. 2010, no. 1, pp. 3-8.

[3] PASQUALE, Cavaliere. Ironmaking and Steelmaking Processes: Greenhouse Emissions, Control, and Reduction. Cham, Switzerland, Springer International Publishing AG, 2016. 466 p.

[4] SANAKULOV, K. S., KHASANOV, A. S. Processing of copper slag production. Tashkent: Fan. 2016. 256 p.

[5] FEDOROV, A. N., DOSMUKHAMEDOV, N. T., ZHOLDASBAYEV, E. E., LUKAVIY, S. L. High copper liquidus temperature of the slag and the solubility of copper oxide in the system $\mathrm{Cu}_{2} \mathrm{O}-\mathrm{FeO}-\mathrm{CaO}-\mathrm{SiO}_{2}$. Tsvetnye metally. 2016, no. 9, pp. 38-42.

[6] LUKAVIY, S. L., FEDOROV, A. N., KHABIEV, R. P.et al. Study the dynamic viscosity of high-copper slag melts. Tsvetnye metally. 2012, no. 2, pp. 32-35.

[7] PARETSKY, V. M., PTITSYN, A. M., TSEMEKHMAN, L. SH., TSYMBULOV, L. B. A New look at the choice of technology for processing impregnated oxide-sulfide platinum-copper-nickel ores. Tsvetnye metally. 2016, no. 6. pp. 38-42.

[8] Method for sorting solid waste and complex for its implementation. Patent for invention RU 2201814, B09B 3/00. Published: 2006.08.27.

[9] MATKARIMOV, S. T., YUSUPKHODJAYEV, A. A., BERDIYAROV, B. T., QODIRJON UGLI NOSIRKHUJAYEV, S., MATKARIMOV, Z. T. Technology of deep processing of copper slags by method of active thermal gravity. International Journal of Advanced Science and Technology. 2020, vol. 29, no. 3, pp. 5633-5639..

[10] Patent for the invention SU 1610197 A1. Method of processing zinc-containing wastes of metallurgical production. Published: 11.30.1990.

[11] LAKERNIK, M.M., PAKHOMOVA, G.N. Metallurgy of zinc and cadmium. Moscow: Metallurgizdat. 2009, pp. 393409.

[12] MATKARIMOV, S. T., NOSIRKHUDJAYEV, S. Q. U., OCHILDIYEV, Q. T., NURALIYEV, O. U. U., KARIMDJONOV, B. R. Technological processes of receiving metals in the conditions of moderate temperatures. International Journal of Innovative Technology and Exploring Engineering. 2019, vol. 8, no. 12, pp. 1826-1828. https://doi.org/10.35940/ijitee.L2856.1081219 